\title{
Terahertz Characteristics of InGaAs with Periodic InAlAs Insertion Layers
}

\author{
Dong Woo Park ${ }^{\mathrm{a}, \dagger, *}$, Jin Soo Kim ${ }^{\mathrm{a}}$, Young Bin $\mathrm{Ji}^{\mathrm{b}}$, Seung Jae $\mathrm{Oh}^{\mathrm{c}}$, Tae-In Jeon ${ }^{\mathrm{d}}$, and Sam Kyu Noh ${ }^{\mathrm{e}, \boldsymbol{\dagger}, *}$ \\ ${ }^{a}$ Division of Advanced Materials Engineering, Chonbuk National University, Jeonju 54896, Republic of Korea \\ ${ }^{b}$ Gimhae Biomedical Center, Gimhae Industry Promotion and Biomedical Foundation, Gyeongsangnam-do 50969, Republic of Korea \\ ${ }^{c}$ YUHS-KRIBB Medical Convergence Research Institute, Yonsei University College of Medicine, Seoul 03722, Republic of Korea \\ ${ }^{d}$ Division of Electrical and Electronics Engineering, Korea Maritime and Ocean University, Busan 49112, Republic of Korea \\ ${ }^{e}$ Division of Physics and Semiconductor Science, Dongguk University, Seoul 04620, Republic of Korea
}

Received November 21, 2018; revised December 1, 2018; accepted December 3, 2018

\begin{abstract}
We presented terahertz $(\mathrm{THz})$ generation and detection characteristics of an InGaAs epilayer with periodic-InAlAs insertion layers (InGaAs-PIL). The peak-to-peak current signal (PPCS) from a THz transmitter with the InGaAs-PIL was three times higher than that of a simple InGaAs epilayer. Moreover, the detection properties of a THz receiver with the low-temperature grown (LT) InGaAs-PIL showed more than twenty-five times higher than that of the LT-InGaAs epilayer. The PPCS of the LT-InGaAs-PIL was significantly improved with increasing the periods of the InAlAs insertion layer.
\end{abstract}

Keywords: Terahertz, Molecular beam epitaxy, Low-temperature growth, Indium gallium arsenide, Multiple quantum well

\section{Introduction}

Usually, so called terahertz (THz) wave is related to the frequency range from 0.1 to $10 \mathrm{THz}$ corresponding to the wavelengths from 30 to $3000 \mu \mathrm{m}$ and the energy gaps from 0.42 to $42 \mathrm{meV}$, respectively. THz wave has been actively studied for the applications of astronomy, analytical science, communication technology, and biological science due to low energy loss and high frequency [1-5]. THz wave can achieve faster data transmission and have more information than GHz system in electronics. Also in optics, $\mathrm{THz}$ wave can apply to imaging, sensing, and absorption spectrum. Furthermore, $\mathrm{THz}$ can be used for nondestructive and non-harmful tomography to live objects. However, it has been difficult for $\mathrm{THz}$ region to realize for the applications. For example, $\mathrm{THz}$ characteristics for electronic applications using the transport type, such as impact ionization avalanche transit-time diode, Gunn diode, and resistance temperature detector, significantly decrease over the frequency of $0.1 \mathrm{THz}$. Also, THz characteristics of optical applications using transition type such as quantum cascade laser decrease under the frequency of $10 \mathrm{THz}$. Recently, THz technologies including transmitters

\footnotetext{
${ }^{\dagger}$ This study was conducted while the author was working at Korea Research Institute of Standards and Science

*Corresponding author

E-mail: dwpark@etri.re.kr, sknoh@dongguk.edu
}

and receivers have been drastically improved mostly due to successful supply of femto-second (fs) pulse laser such as a Ti:sapphire laser.

Typically, low-temperature (LT) grown GaAs, which has high resistivity, high mobility, and short carrier lifetime $[6,7]$, have been used for the $\mathrm{THz}$ generation and detection using photoconductive effect $[8,9]$. The LT-GaAs layer is typically grown at the substrate temperature $\left(T_{\mathrm{s}}\right)$ around $300{ }^{\circ} \mathrm{C}$, which is relatively lower than its optimum $T_{\mathrm{s}}$ window, under arsenic (As)-rich condition [10,11]. As a result, the LT-GaAs has many defects largely consisting of a high density of As antisites. The antisite, $\mathrm{As}_{\mathrm{Ga}}$, can generate defect levels in the energy band gap, working as non-radiative recombination centers of carriers. Nonradiative recombination process of carriers can result in the decrease in carrier lifetime, usually less than $200 \mathrm{fs}$ [12]. In addition, the resistance of the LT-GaAs is measured over $\sim \mathrm{M} \Omega$. In terms of optical communication system using an optical fiber, GaAs $\left(E_{G}=1.42 \mathrm{eV}, \lambda=873 \mathrm{~nm}\right)$ is not suitable for the wavelength windows of 1.3 and $1.5 \mu \mathrm{m}$. On the other hand, $\operatorname{In}_{0.53} \mathrm{Ga}_{0.47} \mathrm{As}\left(\mathrm{E}_{\mathrm{G}}=0.816 \mathrm{eV}, \lambda=\right.$ $1520 \mathrm{~nm}$ ) lattice-matched to $\mathrm{InP}$ can be used to $\mathrm{THz}$ application for the wavelength window of $1.55 \mu \mathrm{m}$ in fiberoptic communication. However, LT-InGaAs has lower resistance and longer carrier lifetime than LT-GaAs [1214]. These intrinsic properties may lead to relatively lower amplitude of current signal and shorter cutoff frequency compared to those of LT-GaAs. 
In this paper, the $\mathrm{THz}$ characteristics of $\mathrm{In}_{0.53} \mathrm{Ga}_{0.47} \mathrm{As}$ (InGaAs) are improved by periodic $\mathrm{In}_{0.52} \mathrm{Al}_{0.48} \mathrm{As}$ (InAlAs) insertion layer (InGaAs-PIL). For comparison, simple InGaAs epilayers grown at different conditions were investigated.

\section{Experimental details}

InGaAs epilayers and InGaAs-PIL were grown on semiinsulating InP:Fe (100) substrate by using a Riber32P molecular beam epitaxy (MBE) with solid sources. The InGaAs epilayers and InGaAs-PIL were lattice-matched to InP. The growth rate and V/III ratio for InGaAs were estimated to be $2.78 \mathrm{~s}^{-1}$ and 12 , respectively. All the epilayers were grown on a $300 \mathrm{~nm}$-thick InAlAs buffer layer. The growth temperatures for the growth of InGaAs were $250{ }^{\circ} \mathrm{C}$ (LT-InGaAs) and $480^{\circ} \mathrm{C}$ (HT-InGaAs). The InGaAs-PIL was grown at the growth temperatures of $250{ }^{\circ} \mathrm{C}$ (LT-InGaAs-PIL) and $400^{\circ} \mathrm{C}$ (HT-InGaAs-PIL). InGaAs total thickness of the LT-InGaAs-PIL was fixed to $500 \mathrm{~nm}$. Three different periods $(10,25$, and 50$)$ for the InGaAs-PIL with a $10 \mathrm{~nm}$-thick InAlAs were inserted to the InGaAs layer to get high resistance. The InGaAs layers of LT-InGaAs and LT-InGaAs-PIL were doped with beryllium (Be) at a doping concentration of $210^{18} \mathrm{~cm}^{-3}$ for carrier compensation. LT-GaAs was annealed inside an MBE chamber at $600{ }^{\circ} \mathrm{C}$ for $10 \mathrm{~min}$ for recrystallization. LT-InGaAs and LT-InGaAs-PIL were annealed in a rapid thermal annealing system at $550^{\circ} \mathrm{C}$ for $10 \mathrm{~min}$ for recrystallization and activation of $\mathrm{Be}$ working as p-type dopants. Table I shows the growth parameters for the samples. Figure 1 shows a layout of photo-mask for

Table I. Growth parameters of InGaAs, InGaAs-PIL, and LTGaAs.

\begin{tabular}{ccccc}
\hline \hline Sample & $\begin{array}{c}\text { Growth } \\
\text { Temperature }\end{array}$ & $\begin{array}{c}\text { InGaAs } \\
\text { total } \\
\text { thickness }\end{array}$ & $\begin{array}{c}\text { Thickness of } \\
\text { a period } \\
\text { (InGaAs/ } \\
\text { InAlAs) }\end{array}$ & Periods \\
\hline HT-InGaAs & $480{ }^{\circ} \mathrm{C}$ & $1 \mu \mathrm{m}$ & $1 \mu \mathrm{m}$ & $\mathrm{n} / \mathrm{a}$ \\
HT-InGaAs-PIL & $400{ }^{\circ} \mathrm{C}$ & $500 \mathrm{~nm}$ & $10 \mathrm{~nm} / 10 \mathrm{~nm}$ & 50 \\
LT-InGaAs & $250{ }^{\circ} \mathrm{C}$ & $1 \mu \mathrm{m}$ & $1 \mu \mathrm{m}$ & $\mathrm{n} / \mathrm{a}$ \\
LT-InGaAs-PIL (10) & $250^{\circ} \mathrm{C}$ & $500 \mathrm{~nm}$ & $50 \mathrm{~nm} / 10 \mathrm{~nm}$ & 10 \\
LT-InGaAs-PIL (25) & $250^{\circ} \mathrm{C}$ & $500 \mathrm{~nm}$ & $20 \mathrm{~nm} / 10 \mathrm{~nm}$ & 25 \\
LT-InGaAs-PIL (50) & $250^{\circ} \mathrm{C}$ & $500 \mathrm{~nm}$ & $10 \mathrm{~nm} / 10 \mathrm{~nm}$ & 50 \\
LT-GaAs & $250^{\circ} \mathrm{C}$ & $1 \mu \mathrm{m}$ & $1 \mu \mathrm{m}$ & $\mathrm{n} / \mathrm{a}$ \\
\hline
\end{tabular}

transmission line antenna (Tx) and dipole antenna (Rx). For the Tx, the line width of transmission line was $10 \mu \mathrm{m}$. The distance between transmission lines was $80 \mu \mathrm{m}$. For the $\mathrm{Rx}$, a Tx was added with a dipole antenna having length of $20 \mu \mathrm{m}$ and distance of $5 \mu \mathrm{m}$ between two dipoles. For the fabrication of $\mathrm{THz}$ devices, electrodes with $\mathrm{Ti}(30 \mathrm{~nm}) / \mathrm{Au}$ $(200 \mathrm{~nm})$ were realized by using an e-beam evaporator. To verify characteristics of fabricated photoconductive antennas, we used a homemade THz-time domain spectroscopy (TDS) system that was driven by femto-second laser pulses to generate and detect $\mathrm{THz}$ waves. We used two off-axis parabolic reflectors to collimate and focus $\mathrm{THz}$ waves onto $\mathrm{Rx}$. Laser pulses generated by a Ti:sapphire mode-locked laser with durations of $60 \mathrm{fs}$ at a repetition rate of $83 \mathrm{MHz}$. The center wavelength of the pulses is $780 \mathrm{~nm}$. A more detailed description of THz-TDS system is presented in a previous report [15]. The measured THz signal was converted to frequency spectrum by fast Fourier transformation for analyzing frequency dependent characteristics.

\section{Results and discussion}

Figure 2(a) shows the thickness-dependent secondary ion mass spectroscopy (SIMS) profile of LT-InGaAs-PIL (25). While the SIMS intensities of As and In were consistent with time, the profiles of $\mathrm{Ga}$ and $\mathrm{Al}$ were changed. Figure 2(b) shows 2theta-omega scanning curves of HT-InGaAs-PIL and LT-InGaAs-PIL (50) obtained from high resolution X-ray diffraction (HR-XRD). For the HTInGaAs-PIL, the several satellite peaks were clearly observed in the HR-XRD rocking curve. However, there was no peak for the LT-InGaAs-PIL (50). This is due to the low crystalline quality for the LT-InGaAs-PIL with defects in the epilayer and at the interface between InGaAs and InAlAs.

Figure 3 shows the transmission electron microscopy (TEM) images of (a) LT-InGaAs epilayers and (b) LTInGaAs-PIL (50), where the defects such as $\mathrm{As}_{\mathrm{Ga}}$ antisites were observed. These defects can lead to extremely short carrier lifetime less than 1 picosecond (ps) $[16,17]$.

The optical properties of LT-InGaAs-PIL and HTInGaAs-PIL were analyzed by using PL spectroscopy. In Fig. 4(a), the emission wavelength of HT-InGaAs-PIL was measured to be $1590 \mathrm{~nm}$ at $10 \mathrm{~K}$. However, the PL spectrum was not observed for the LT-InGaAs-PIL (50) mainly due to high non-radiative recombination rate of

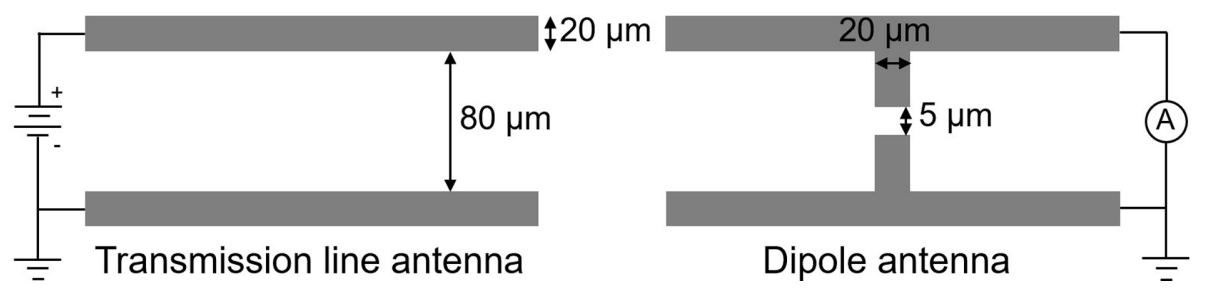

Figure 1. Configuration of transmission line antenna for THz generation and dipole antenna for THz detection. 

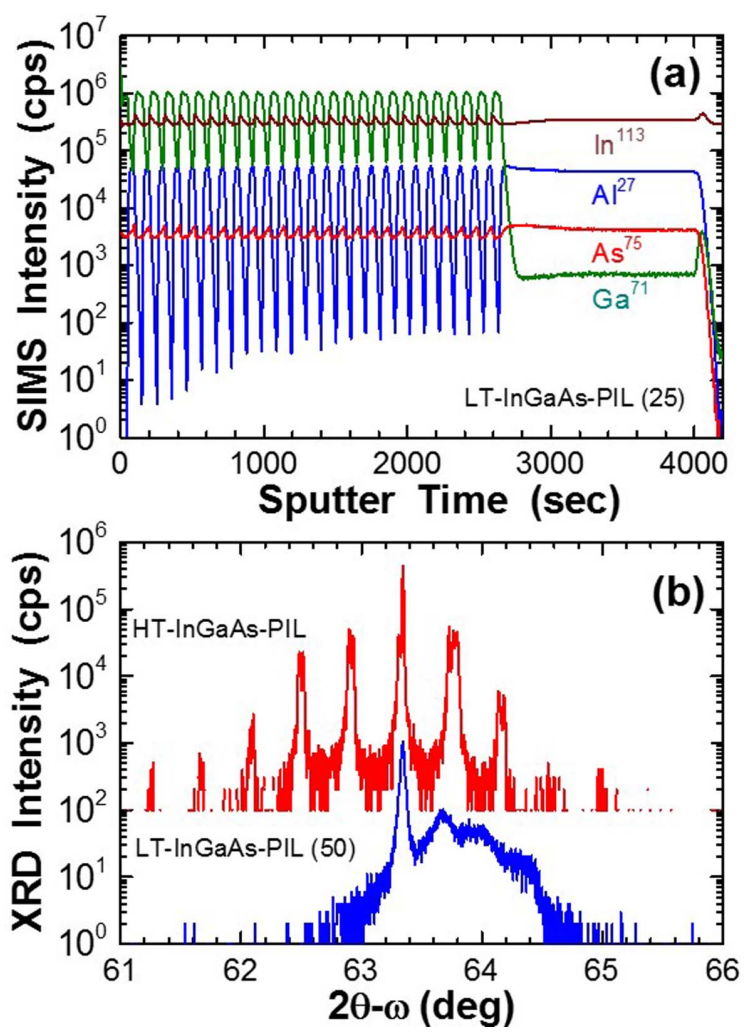

Figure 2. (a) Thickness-dependent SIMS profile for changing measurement of In, Ga, Al, and As in LT-InGaAs-PIL (25) and (b) 2theta-omega scanning for determination of crystalline quality of InGaAs-PIL.
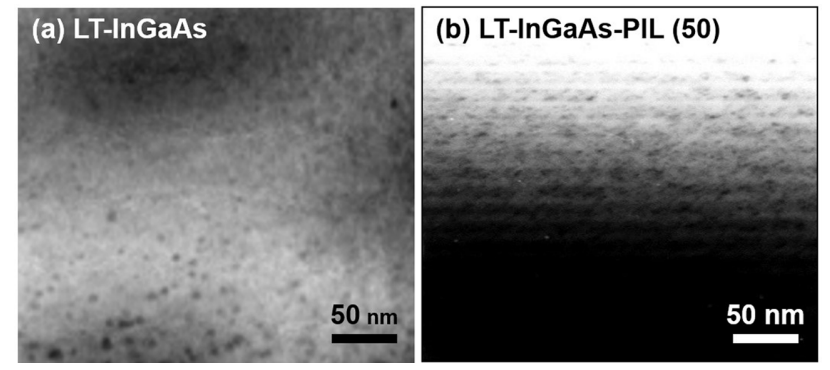

Figure 3. Observation of high $\mathrm{As}_{\mathrm{Ga}}$ antisite TEM analysis in (a) LT-InGaAs and (b) LT-InGaAs-PIL (50).

carriers, mainly caused by a large number of defects, over radiative component. Figure 4(b) shows the decay curves of LT-InGaAs, LT-InGaAs-PIL (50), and HT-InGaAs-PIL. The LT-InGaAs and LT-InGaAs-PIL (50) show fast decay characteristics, indicating to short carrier lifetime, due to effect of the non-radiative recombination component. These properties may increase the ability of $\mathrm{THz}$ generation and detection. For the characterization of carrier lifetime, the back side of a SI-InP substrate was polished to enhance the transmission of a probe beam. Carrier lifetimes of LT-InGaAs, LT-InGaAs-PIL (50) and HT-InGaAs-PIL were measured to be $1.4,0.95$ and $3.6 \mathrm{ps}$, respectively. The very short carrier lifetime at picosecond level is largely due to defects, mostly $\mathrm{As}_{\mathrm{Ga}}$ antisites [18]. That is, trapping level for carrier due to defects can result in short carrier lifetime [19]. Since LT-growth of InAlAs typically generates more
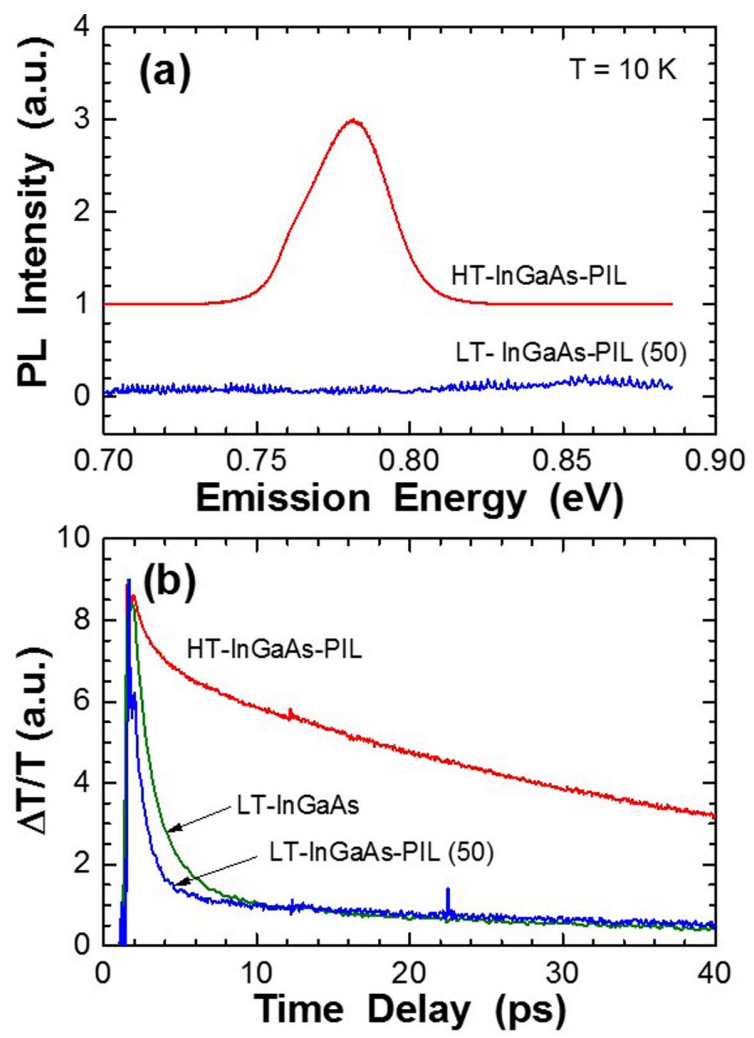

Figure 4. Radiation characteristics of (a) HT-InGaAs-PIL and LT-InGaAs-PIL (50) using PL spectroscopy and (b) carrier life time measurement of HT-InGaAs-PIL, LT-InGaAs-PIL (50), and LT-InGaAs using pump-probe spectroscopy.

defects between InAlAs and InGaAs, carrier lifetime of LTInGaAs-PIL was shorter than that of LT-InGaAs. For the HT-InGaAs-PIL, the InGaAs layer has relatively low defects. However, the InAlAs layer has many As antisites, which can work as carrier trapping sites. This can lead to high resistance and short carrier lifetime, enhancing the $\mathrm{THz}$ characteristics.

Figure 5 shows current signals and spectra of $\mathrm{THz}$ transmitters with a SI-GaAs substrate, HT-InGaAs, and HT-InGaAs-PIL. In case of photoconductive effect, as a femto-second laser pulse arrive at the transmission line of the Tx, holes and electrons are generated because the energy of the $780 \mathrm{~nm}$ laser beam is greater than that of the sample's band gap. After that, the DC bias voltage on the order of $10^{6} \mathrm{~V} / \mathrm{m}$ is applied to the Tx. The generated carriers are immediately accelerated by the electric field, a resulting transient photocurrent flows and a dipole moment is formed in the substrate. $\mathrm{THz}$ waves which are proportional to Maxwell's equation radiate to free space. High resistive silicon lens was used to collimate the $\mathrm{THz}$ waves. The laser beam should be focused onto positive bias side due to asymmetry $\mathrm{THz}$ generation characteristic for DC bias pole. In case of photo-Dember effect, the generated electrons and holes move in opposite directions, and the band bending is accelerated by the dipole to generate $\mathrm{THz}$ wave. $\mathrm{THz}$ signals were detected by LT- 

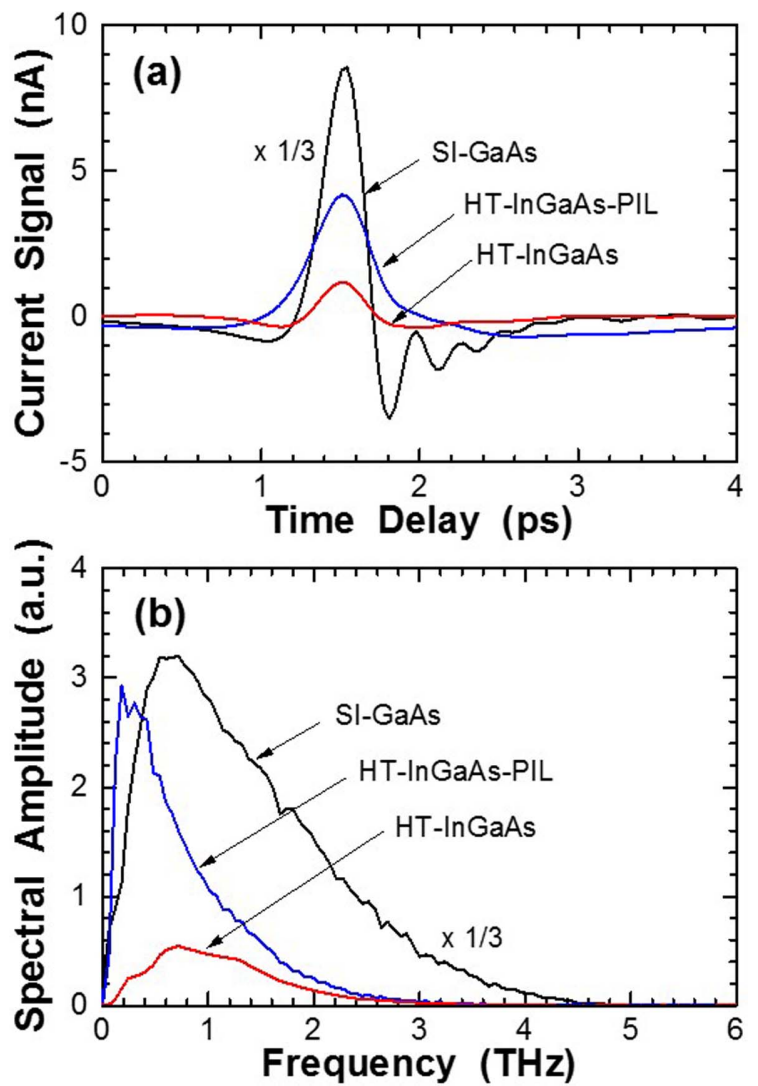

Figure 5. THz generation characteristics of SI-GaAs, HTInGaAs, and HT-InGaAs-PIL for (a) current signals and (b) spectra of THz.

GaAs. The peak-to-peak current signal (PPCS) of the SIGaAs, HT-InGaAs, and HT-InGaAs-PIL were measured to be 36, 1.6, and $5 \mathrm{nA}$, respectively. The energy of generated $\mathrm{THz}$ wave from the SI-GaAs, HT-InGaAs, and HTInGaAs-PIL were existed up to $4.5,3$, and $3 \mathrm{THz}$, respectively, where the SI-GaAs generated the highest current signal due to high resistance. The HT-InGaAs has lower current signal and shorter cutoff frequency compared to those of the SI-GaAs. According to the previous reports, when the growth temperature for InAlAs was from 350 to $400{ }^{\circ} \mathrm{C}$, electrical properties was changed to semi-insulator due to high density of defects [20]. As a result, the InGaAs-PIL with InAlAs has high resistance. Although the PPCS of HT-InGaAs-PIL was increased over three times higher than that of InGaAs epilayer, cutoff frequency still remains at $3 \mathrm{THz}$.

Figure 6 shows current signals and spectra of $\mathrm{THz}$ receivers based on LT-GaAs, LT-InGaAs, and LT-InGaAsPIL. The $\mathrm{THz}$ detection method is photoconductive sampling, in which the $\mathrm{THz}$ pulse irradiated to the antenna forms an electric field between the electrodes to detect the current proportional to the $\mathrm{THz}$ intensity. The generated $\mathrm{THz}$ electric field lasts a few ps. All $\mathrm{THz}$ signals were obtained by SI-GaAs under DC bias voltage on the order of $10^{6} \mathrm{~V} / \mathrm{m}$. The PPCS and cutoff frequency for LT-GaAs (LT-InGaAs) were $22 \mathrm{nA}(0.5 \mathrm{nA})$ and $4.5 \mathrm{THz}(3 \mathrm{THz})$,
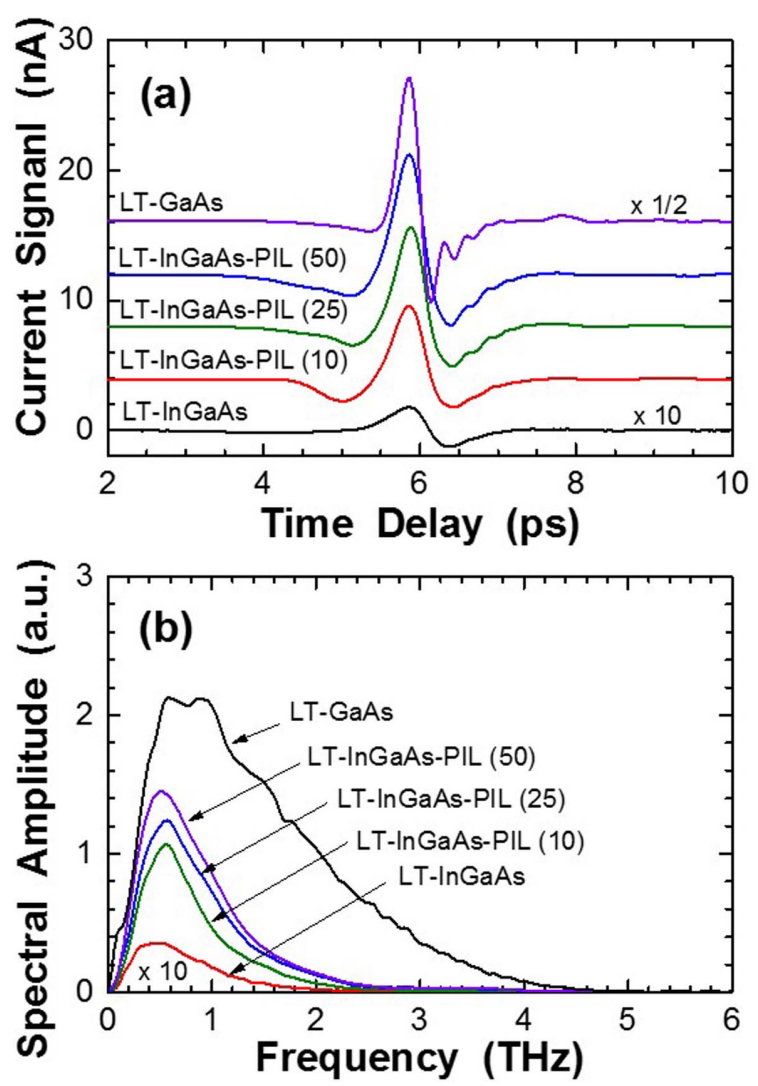

Figure 6. THz detection characteristics of LT-GaAs, LTInGaAs epilayer, and LT-InGaAs-PIL for (a) current signals and (b) spectra of $\mathrm{THz}$.

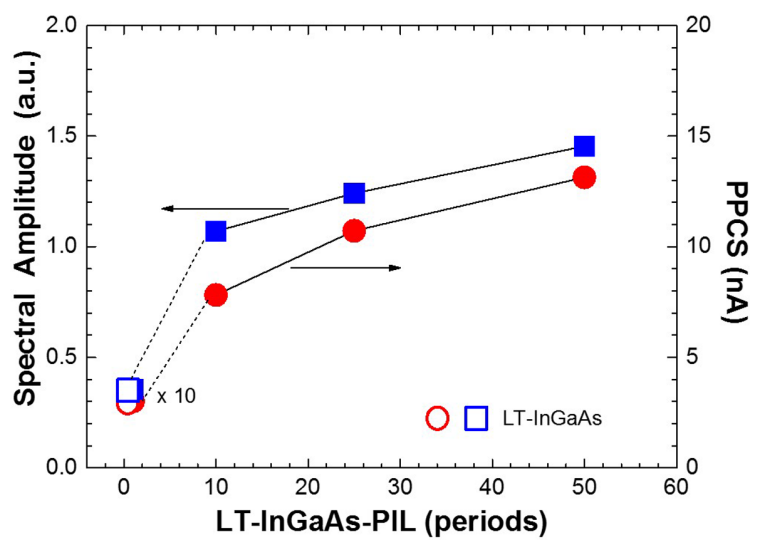

Figure 7. Increased THz detection properties depending on the periods of InAlAs.

respectively. The PPCSs of InGaAs-PIL (10), HT-InGaAsPIL (25), and HT-InGaAs-PIL (50) were measured as 8, 10.5 , and $13.0 \mathrm{nA}$, respectivley, which are larger than that of LT-InGaAs. However, the cutoff frequency of LTInGaAs-PIL was not changed with periods. This is related that the InAlAs layers can generate higher photoconductive effect for a $\mathrm{THz}$ device due to high resistance and trapping effect.

Figure 7 shows the summary on spectral amplitude and the PPCS of LT-InGaAs-PIL with different InAlAs periods. Although the active InGaAs layer had same thickness for 
all samples, the current signal was effectively increased by inserting the InAlAs layers.

\section{Conclusions}

In summary, for the enhancement of $\mathrm{THz}$ generation and detection, InAlAs layers were periodically inserted to an InGaAs epilayer to get relatively high resistance and short carrier lifetime. The PPCS from a THz transmitter with the InGaAs-PIL ( $5 \mathrm{nA}$ ) showed three times higher than that of a simple InGaAs epilayer without the InAlAs insertion layer (1.6 nA). Moreover, the detection properties of a $\mathrm{THz}$ receiver with the LT-InGaAs-PIL ( $8 \mathrm{nA})$ showed sixteen times higher than that of the LT-InGaAs epilayer ( $0.5 \mathrm{nA})$. The PPCS of the LT-InGaAs-PIL was improved from 8 to $13 \mathrm{nA}$ with increasing the periods of the InAlAs layers from 10 to 50 . This is related that InAlAs layers can make higher photoconductive effect for $\mathrm{THz}$ device due to high resistance and trapping effect via defects.

\section{Acknowledgments}

The authors would like to thank the National Research Foundation for supporting the Global Research Laboratory (GRL) project (2007-00011) for this study. This research was supported by National Research Foundation of Korea (NRF), the Korea Government (MSIP) (Grant No. 2016R1 A2B4012523).

\section{References}

[1] M. Tonouchi, Nat. Photon. 1, 97 (2007).

[2] S. Wang and X. C. Zhang, J. Phys. D: Appl. Phys. 37, R1 (2004).

[3] S. J. Oh, C. Kang, I. Maeng, J. H. Son, N. K. Cho, J. D. Song, W. J. Choi, W. J. Cho, and J. I. Lee, Appl. Phys. Lett. 90, 131906 (2007).

[4] O. Mitrofanov, W. Yu, R. J. Thompson, Y. Jiang, I. Brener, W. Pan, C. Berger, W. A. de Heer, and Z. Jiang, Appl. Phys. Lett. 103, 111105 (2013).

[5] D. W. Park, Y. B. Ji, J. Hwang, C. R. Lee, S. J. Lee, J. O. Kim, S. K. Noh, S. J. Oh, S. H. Kim, T. I. Jeon, K. U. Jeong, and J. S. Kim, Sci. Rep. 6, 36094 (2016)

[6] P. Maraghechi and A. Y. Elezzabi, Opt. Exp. 18, 27336 (2010).

[7] H. Tanoto, J. H. Teng, Q. Y.Wu, M. Sun, Z. N. Chen, S. A. Maier, B. Wang, C. C. Chum, G. Y. Si, A. J. Danner, and S. J. Chua, Sci. Rep. 3, 2824 (2013).

[8] G. Segschneider, F. Jacob, T. Löffler, H. G. Roskos, S. Tautz, P. Kiesel, and G. Döhler, Phys. Rev. B 65, 125205 (2002).

[9] S. Rihani, R. Faulks, H. E. Beere, I. Farrer, M. Evans, D. A. Ritchie, and M. Pepper, Appl. Phys. Lett. 96, 091101 (2010).

[10] J. L. Pan, J. E. Mcmanis, T. Osadchy, L. Grober, J. M.Woodall, and P. J. Kindlmann, Nat. Mater. 2, 375 (2003).

[11] A. Shen, H. Ohno, Y. Horikoshi, S. P. Guo, Y. Ohno, and F. Matsukura, Appl. Surf. Sci. 130, 382 (1998).

[12] C. Baker, I. S. Gregory, M. J. Evans, W. R. Tribe, E. H. Linfield, and M. Missous, Opt. Exp. 13, 9639 (2005).

[13] D. W. Park, Ph.D. thesis, Chonbuk National University, 2016.

[14] D. W. Park, J. S. Kim, S. K. Noh, Y. B. Ji, and T. I. Jeon, Appl. Sci. Converg. Technol. 21, 264 (2012).

[15] N. Katzenellenbogen and D. Grischkowsky, Appl. Phys. Lett. 58, $222(1991)$

[16] L. L. Anisimova, A. K. Gutakovskii, I. V. Ivonin, V. V. Preobrazhenskii, M. A. Putyato, B. R. Semyagin, and S. V. Subach, J. Struc. Chem. 45, S96 (2004).

[17] H. Künzel, J. Böttcher, R. Gibis, and G. Urmann, Appl. Phys. Lett. 61, 1347 (1992).

[18] D. Vignaud, J. F. Lampin, E. Lefebvre, M. Zaknoune, and F. Mollot, Appl. Phys. Lett. 80, 4151 (2002).

[19] N. Chimot, J. Mangeney L. Joulaud, P. Crozat, H. Bernas, K. Blary, and J. F. Lampin, Appl. Phys. Lett. 87, 193510 (2005).

[20] J. Oh, P. Bhattacharya, Y. Chen, O. Aina, and M. Mattingly, J. Elec. Mater. 19, 435 (1990). 